\title{
Sterol Synthesis and Low Density Lipoprotein Clearance In Vivo in the Pregnant Rat, Placenta, and Fetus

\author{
Sources for Tissue Cholesterol during Fetal Development
}

\author{
William M. Belknap and John M. Dietschy \\ Departments of Pediatrics and Internal Medicine, University of Texas Southwestern Medical Center at Dallas, Dallas, Texas $75235-9063$
}

\begin{abstract}
Whereas the greatest relative increase in body mass occurs during the third trimester of fetal life, the source of the cholesterol that supports this growth is uncertain. These studies used $\left[{ }^{3} \mathrm{H}\right]$ water and ${ }^{125} \mathrm{I}$-cellobiose-labeled low density lipoproteins to quantitate absolute rates of cholesterol acquisition in vivo by the fetus of the rat. Preliminary studies demonstrated that $\left[{ }^{3} \mathrm{H}\right]$ water administered intravenously to the mother rapidly equilibrated with the body pool of water in the fetus and that $22-\mu \mathrm{g}$ atoms of $\mathrm{H}$ from the water pool were incorporated into each micromole of newly synthesized cholesterol. After administration of $\left[{ }^{3} \mathrm{H}\right]$ water to pregnant rats, the rates of sterol synthesis per $100 \mathrm{~g}$ of whole body weight were severalfold higher in the fetus than in the dams. Individual organs of the dam such as the liver, however, had much higher synthetic rates than those in the fetus. When maternal hepatic cholesterol synthesis was suppressed by cholesterol feeding, newly synthesized cholesterol disappeared from the maternal blood yet there was essentially no change in the rate of appearance of newly synthesized sterol in the fetus, placenta, and fetal membranes. The placenta did take up low density lipoproteins at rates equal to about one-third of that seen in the maternal liver, but none of the apolipoprotein or cholesterol was transferred to the fetus. These studies indicate that the rat fetus receives little or no cholesterol from the mother but, rather, satisfies its need for cholesterol during fetal development through local synthesis. Furthermore, the fetal membranes appear to be an important site for sterol synthesis in the fetal compartment.
\end{abstract}

\section{Introduction}

The metabolically active pool of cholesterol in any tissue can be derived from only two sources, i.e., de novo synthesis from acetyl CoA and uptake of sterol carried in a particular lipoprotein class. Rates of such cholesterol synthesis and uptake of sterol carried in LDL have now been measured in the organs of a variety of animal species in vivo under different physiological conditions (1-5). In general, such studies have revealed

Address reprint requests to Dr. Belknap, Department of Pediatrics, Division of Gastroenterology and Nutrition, University of Texas Southwestern Medical Center at Dallas, 5323 Harry Hines Boulevard, Dallas, TX 75235-9063.

Received for publication 11 April 1988 and in revised form 27 June 1988.

J. Clin. Invest.

(c) The American Society for Clinical Investigation, Inc. 0021-9738/88/12/2077/09 \$2.00

Volume 82, December 1988, 2077-2085 that local synthesis is quantitatively more important to the tissue sterol economy than uptake of lipoprotein cholesterol (6), although in certain circumstances this may not be true for endocrine tissues (7). During the early development of animals and man and particularly during fetal development, there is a marked need for new sterol. As body mass increases exponentially, cholesterol is required for new membrane synthesis, for maintenance of existing membranes and for the synthesis of hormones and bile acids (8). As in the individual organs of the adult, this sterol could be acquired by either synthesis de novo within the fetal compartment or by transfer from the maternal compartment to the fetus through uptake of cholesterol carried in lipoproteins.

Previous work has revealed high rates of cholesterol synthetic activity in human fetal organ cultures using tissue obtained from second trimester abortuses (9). Furthermore, both the quantity and activity of the rate-limiting enzyme in the cholesterol biosynthetic pathway in the fetus has been shown to change in response to alterations in fetal plasma LDL-cholesterol levels (10). These observations suggest that the human fetus is capable of regulated sterol synthesis and that such synthesis could account for much of the sterol required during intrauterine growth. On the other hand, in tissue culture human placental trophoblasts appear to preferentially utilize LDL-cholesterol over newly synthesized sterol for tissue growth and hormone synthesis (11). Presumably a similar dependency for lipoprotein cholesterol exists for the placenta in vivo, although this is by no means certain.

It is now possible to examine these important questions directly since methods have become available that permit assessment of absolute rates of both cholesterol synthesis and LDL-cholesterol uptake in the tissues of the live animal. Using these methods the current studies were undertaken to determine the extent to which the fetus, placenta, and fetal membranes are dependent upon maternal sterol synthesis and lipoprotein-cholesterol for growth and development. In order to examine these important questions, four groups of studies were undertaken. First, it was necessary to define the rate at which the radiolabeled precursor, $\left[{ }^{3} \mathrm{H}\right]$ water, equilibrates with the fetal compartment and to determine the hydrogen-to-carbon incorporation ratio during fetal sterol synthesis. Second, the absolute rates of sterol synthesis in the fetus, placenta and fetal membranes were measured in vivo during the exponential growth phase of late gestation. Third, the effect of altering maternal sterol synthesis rates on the acquisition of newly synthesized cholesterol by the fetus was examined. Finally, the rates of LDL-cholesterol uptake by the tissues of the pregnant rat, fetus, and placenta were measured. The results of these studies indicate that the fetus is capable of synthesizing essentially all of the cholesterol that it requires for growth and development. 


\section{Methods}

Animal preparation. Female Sprague-Dawley-derived rats (Sasco Breeding Laboratories, Inc., Omaha, NE), were purchased in the weight range of 150 to $170 \mathrm{~g}$. Both virgin and pregnant female rats were obtained. The latter were known to have been bred on a specific date as confirmed by sperm positivity. Upon arrival, all animals were housed in an isolation room with alternating 12-h periods of light (1500-0300 hours) and dark (0300-1500 hours), and were allowed free access to water and rodent diet (Teklad Laboratory Animal Diets, Winfield, IA) for at least $2 \mathrm{wk}$ before being used. In one experiment, groups of animals were fed $2 \%$ (wt/wt) cholesterol in the diet for $4 \mathrm{~d}$ before being studied. The animals in the various experimental groups were weighed on a regular basis and plasma cholesterol concentrations were determined in groups of animals killed throughout the gestation period.

Determination of the rate of $\left[{ }^{3} \mathrm{H}\right]$ water equilibration between the maternal and fetal circulations. When a single bolus of $\left[{ }^{3} \mathrm{H}\right]$ water is administered intravenously to the adult rat, the specific activity of the plasma water decreases with respect to time for several minutes as the unlabeled tissue water comes into equilibrium with the labeled plasma water. In studies in both the virgin and pregnant female rat, it was found that $\sim 20 \mathrm{~min}$ was required for the isotope to equilibrate with the body pool of water and for the specific activity of the plasma water to become constant (12). Thus, the specific activity of plasma water determined $60 \mathrm{~min}$ after the intravenous administration of $\left[{ }^{3} \mathrm{H}\right]$ water is slightly lower than the mean specific activity of plasma water throughout the $1-\mathrm{h}$ period. From detailed time-courses it has been found that the specific activity values measured at 60 min must be multiplied by a factor of 1.09 to obtain the mean specific activity of plasma (and, therefore, tissue) water integrated over the 1-h that synthesis rates were measured (12). In these new studies it was necessary to determine a second correction factor to adjust for the further small delay in isotopic equilibration between the maternal plasma and that of the fetus. To determine this factor, pregnant rats in late gestation were administered $100 \mathrm{mCi}$ of $\left[{ }^{3} \mathrm{H}\right]$ water under light ether anesthesia and blood samples were then obtained at 2, 5, 10, 15, 20,30, and 60 $\mathrm{min}$. At the time of sampling the animals were again anesthetized with ether and a midabdominal incision was made. The blood sample was immediately obtained from the abdominal aorta, and both horns of the bicornuate uterus were quickly separated from the maternal carcass. At the same time blood was aspirated from four to five fetuses and pooled into a single sample. These specimens of maternal and fetal blood were centrifuged and the specific activity of the plasma water was calculated using the following formula:

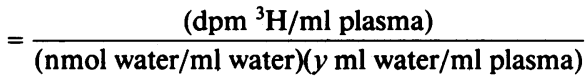

The factor $y$ was determined to equal 0.92 for maternal plasma and 0.96 for fetal plasma.

Determination of the number of hydrogen atoms from plasma water incorporated into cholesterol. To accurately calculate absolute rates of sterol synthesis, it was next necessary to determine the microgram atoms of $\mathbf{H}$ that are incorporated into the cholesterol molecule from tissue water during sterol biosynthesis in the fetus. Previous studies have shown that $\sim 21-25-\mu \mathrm{g}$ atoms of $\mathrm{H}$ are incorporated into the sterol molecule from body water during the synthesis of cholesterol in different organs of adult animals (13-15). This value, however, was not available for the fetus. To obtain such information, female rats were placed in cages under fume hoods, given a cholesterol-free diet (ICN Biomedical, Cleveland, $\mathrm{OH}$ ) and allowed access to drinking water to which was added $\left[{ }^{3} \mathrm{H}\right]$ water. After 2 wk the animals were mated and were kept under the same dietary conditions for the next 3 wk. It should be emphasized that throughout this 5-wk period, the animals were given drinking water that contained $\left[{ }^{3} \mathrm{H}\right]$ water at a constant specific activity so that the plasma water specific activity in each animal was also constant throughout this entire period. At a gestational age of $21 \mathrm{~d}$ the animals were anesthetized and blood samples were obtained from both the dams and fetuses. The fetuses, placentas, and maternal livers were then harvested and saponified, and the sterols were extracted. After separation of the sterols on HPLC, both the mass and radioactivity present in the cholesterol peak were quantitated. It should be noted that $>85 \%$ of the sterols in these three tissues were specifically cholesterol. From the absolute specific activity of the plasma water and cholesterol it was then possible to calculate the number of $\mathrm{H}$ atoms derived from the pool of body water that was incorporated into each molecule of cholesterol under these experimental circumstances where essentially all of the sterol in the fetus was newly synthesized (15).

Determination of sterol synthesis rates in vivo. Pregnant rats were studied on days 14,17 , and 21 of the 22 -d gestation. Control virgin female rats, which were the same age and body weight on the day of breeding as those that were impregnated, were studied in parallel. In one experiment, separate groups of pregnant and virgin rats were prefed a high cholesterol diet ( $2 \% \mathrm{wt} / \mathrm{wt}$ ) for $4 \mathrm{~d}$ before study on day 17 of gestation in order to assess the effects of dietary inhibition of hepatic cholesterol synthesis during pregnancy. On the day of the experiments, the experimental animals were administered $100 \mathrm{mCi}$ i.v. of $\left[{ }^{3} \mathrm{H}\right]$ water as a bolus in $1.0 \mathrm{ml}$ of isotonic saline via tail vein catheters, as described previously (16). After $1 \mathrm{~h}$ the animals were anesthetized with ether, a laparotomy was performed, and blood samples were obtained from the abdominal aorta. The animals were then exsanguinated and various organs were removed. These organs, along with the remaining carcass, were saponified (16). In the pregnant animals each fetus, placenta, decidua, and fetal membranes was carefully dissected out and also saponified. Fetal membranes designate the structural membranes adherent to the fetal side of the placenta. These membranes encompass the amniotic fluid, umbilical cord and body of the fetus. The specific activity of the maternal plasma was determined from the blood samples. The tissue samples were saponified in alcoholic $\mathrm{KOH}$ and the sterols were extracted quantitatively and precipitated as the digitonides. The precipitates were then dried under vacuum and the digitonides were split with pyridine. The free sterols were extracted with diethyl ether, dried under vacuum, and assayed for ${ }^{3} \mathrm{H}$ content (16).

The rates of cholesterol synthesis found in vivo in these studies are presented as the nmol of body water that are incorporated into digitonin precipitable sterols (DPS) per unit time. In these studies the tissue sterols were isolated by digitonin precipitation. When these digitonides were split and analyzed by high performance liquid chromatography and gas liquid chromatography, $85-95 \%$ of the DPS was specifically cholesterol in the liver of the dams and in the fetuses and placentas. Thus, in this paper we have used interchangeably the terms DPS and cholesterol. These rates of synthesis are calculated using the following formula (16):

$=\frac{\left(\mathrm{dpm}\left[{ }^{3} \mathrm{H}\right] \mathrm{DPS}\right)}{(\text { time }, \mathrm{h})(\text { tissue weight, } \mathrm{g})(\text { mean sp act of body water, } \mathrm{dpm} / \mathrm{nmol})}$

The mean specific activity of the maternal plasma water equaled 1.09 times the specific activity of the maternal plasma water measured 60 min after administration of the $\left[{ }^{3} \mathrm{H}\right]$ water (see Eq. 1). The mean specific activity of the fetal plasma water equaled 1.09 times 0.91 (i.e., 0.99 , see Results) times the specific activity of the maternal plasma water measured at $60 \mathrm{~min}$ after administration of the $\left[{ }^{3} \mathrm{H}\right]$ water. These rates of synthesis are expressed either as the nanomoles of $\left[{ }^{3} \mathrm{H}\right]$ water incorporated into DPS per hour per gram or as the micromoles of $\left[{ }^{3} \mathrm{H}\right]$ water incorporated into DPS per hour per whole organ. In some cases, whole animal synthesis rates are given as the micromoles of $\left[{ }^{3} \mathrm{H}\right]$ water incorporated into DPS per hour per 100 grams body weight. Fetuses at the gestational ages of 14 and $17 \mathrm{~d}$ were determined to have $15 \%$ more body water $(0.10 \pm 0.001 \mathrm{~g}$ dry weight/g wet $\mathrm{wt})$ than virgin or pregnant rats $(0.25 \pm 0.005 \mathrm{~g} / \mathrm{g})$; fetuses at $21 \mathrm{~d}(0.14 \pm 0.003 \mathrm{~g} / \mathrm{g})$ and

1. Abbreviations used in this paper: DPS, digitonin precipitable sterols. 
all placentas $(0.14 \pm 0.004 \mathrm{~g} / \mathrm{g}) \mathrm{had} 11 \%$ more water. The final data were corrected to account for this disparity between fetuses and fully grown animals.

Lipoprotein preparation. To measure lipoprotein transport rates in the various organs of these animals, LDL was isolated and purified from donor animals. Plasma was obtained from $\sim 80$ rats that had been maintained on a low-cholesterol rodent diet. Rat LDL was harvested in the density range of 1.020 to $1.055 \mathrm{~g} / \mathrm{ml}$ and purified as previously described (3). On polyacrylamide gels, this LDL preparation contained essentially only apolipoprotein B-100. The LDL was then labeled with ${ }^{125}$ I-cellobiose, using the same procedure previously described for labeling with $\left[{ }^{14} \mathrm{C}\right]$ sucrose $(4,17,18)$. The labeled lipoprotein was used within $24 \mathrm{~h}$ of preparation and was passed through a $0.45-\mu \mathrm{m}$ Millipore filter (Millipore Corp., Bedford, MA) just before administration to the experimental animals.

Determination of lipoprotein uptake rates in the various tissues of the experimental animals. Pregnant rats in late gestation and virgin female control animals were fitted with femoral vein catheters and placed in individual restraining cages. At the outset of these studies, each animal was given a priming dose of radiolabeled LDL followed by a continuous 6-h infusion of the same lipoprotein preparation. Using previously measured whole-animal LDL clearance rates, the amount of radioactive $\mathrm{LDL}$ infused per $\mathrm{h}$ was adjusted, relative to the dose given as a bolus, in order to maintain the specific activity of the plasma LDL at an essentially constant level throughout the 6-h period of infusion $(4,19,20)$. Under such conditions the ${ }^{125}$ I-cellobiose-labeled LDL is taken up by the various organs of the body at rates that are linear with respect to time. Since the ${ }^{125}$ I-cellobiose is largely retained by the tissues, accumulation of this radiolabeled compound can be used to calculate the rates of uptake of LDL into the various tissues. Separate groups of experimental and control animals were killed 10 min after administration of the initial bolus and after $6 \mathrm{~h}$ of continuous infusion. Aliquots of the major organs, along with plasma samples, were assayed for their ${ }^{125}$ I content. In addition, in the pregnant animals both the placentas and fetuses were removed and assayed. Tissue spaces and rates of LDL clearance were determined as previously described $(19,20)$. These rates are expressed as the microliters of plasma totally cleared of their LDL content per hour per gram of tissue. These rates also were multiplied by organ weights, normalized to a constant body weight of $100 \mathrm{~g}$, to give clearance rates per whole organ.

Calculations. Where appropriate, the data are presented as mean values \pm 1 SEM. Where necessary, differences in mean values were tested for significance at the $P<0.05$ level using the unpaired $t$ test. Significant differences are indicated in the various figures by an asterisk.

\section{Results}

These studies were designed to determine the major source or sources of the cholesterol used during fetal development for the construction of fetal tissues. These experiments were made possible by development of newer techniques that allow determination of absolute rates of cholesterol synthesis and LDLcholesterol uptake in the organs of the live animal. Before performing specific experiments to identify possible sources of fetal sterol, it was first necessary to explore several features of the experimental system and, in particular, to characterize the equilibration of $\left[{ }^{3} \mathrm{H}\right]$ water between the maternal and fetal circulations and to determine the rate at which fetal tissue incorporates protons from tissue water into newly synthesized sterols.

Characterization of the pregnant rat model. The pregnant and fetal rats used in these experiments exhibited the appropriate physiological parameters as previously reported in a number of publications $(21,22)$. For example, as illustrated in

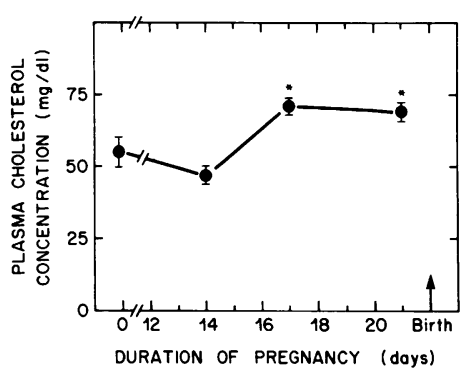

Figure 1. Plasma total cholesterol concentrations in rats during normal pregnancy. The first data point is the mean level in virgin rats. Plasma cholesterol levels at 17 and $21 \mathrm{~d}$ of pregnancy were significantly elevated when compared to those in virgin rats or at $14 \mathrm{~d}$ of pregnancy. The data points represent mean values \pm 1 SEM for levels determined in three to six animals at each time point.

Fig. 1, the plasma cholesterol concentration rose significantly, from about $55 \pm 5$ to $72 \pm 3 \mathrm{mg} / \mathrm{dl}$, during the last trimester of the pregnancy, as has been previously reported (23). There was no corresponding change in the concentration of cholesterol in the liver. This value remained constant at $\sim 2.3 \mathrm{mg} / \mathrm{g}$. Also as anticipated, the weights of the pregnant animals increased significantly more than those of the virgin control animals even when these weights were corrected for the mass of the products of conception (Fig. $2 \mathrm{~A}$ ). Thus, at $21 \mathrm{~d}$ into the normal 22-d gestation period, the weight of the fetuses and placentas averaged $5.2 \pm 0.1 \mathrm{~g}$ and $0.63 \pm 0.01 \mathrm{~g}$, respectively, while the weights of the dams and the virgin control females equaled $307 \pm 8.4$ and $211 \pm 3.3 \mathrm{~g}$, respectively.

Determination of the rate of $\left[{ }^{3} \mathrm{H}\right]$ water equilibration between the maternal and fetal circulations. To utilize the $\left[{ }^{3} \mathrm{H}\right]-$ water method to quantitate rates of sterol synthesis in the fetus, it was first necessary to characterize the time course for the equilibration of the radiolabeled isotope between the maternal and fetal circulations. Since the fetal plasma water represents a separate compartment that must equilibrate across the placenta after the injection of the bolus of $\left[{ }^{3} \mathrm{H}\right]$ water to the

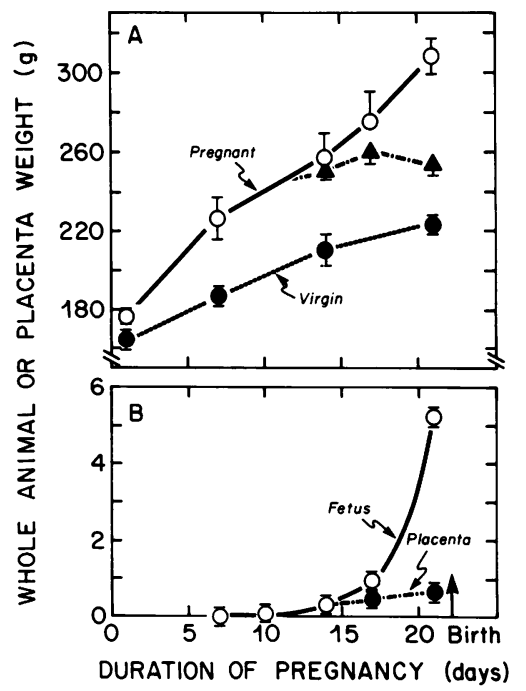

Figure 2. Comparison of the changes in body weight during the study period in pregnant rats and fetuses and in virgin rats. $(A)$ The respective weight gains in pregnant and virgin rats of identical age. In the case of the pregnant animals, both total body weight (solid line) and body weight after subtraction of the weight of the fetuses and placentas (broken line) are shown. $(B)$ The mean weights of the fetuses and placentas at each time point during the pregnancy. Mean values \pm 1 SEM are shown for three to six animals in each group. 
mother, the rate of equilibration must be determined in order to obtain the mean plasma water specific activity in the fetus over the 1-h experimental period. In order to obtain this information, a group of females that had been pregnant for 20-22 d was given an intravenous injection of $\left[{ }^{3} \mathrm{H}\right]$ water as a bolus. Groups of these animals were then killed at various times during the subsequent $60-\mathrm{min}$ period and the specific activity of the fetal and maternal plasma was determined. As shown in Fig. 3, the specific activity of the fetal plasma water (and of the fetal hepatic water) equaled that of the mother after $\sim 20 \mathrm{~min}$. From the area under this curve, it was calculated that the mean specific activity of the fetal plasma water over the 1-h period of observation equaled the specific activity of the fetal plasma measured at $60 \mathrm{~min}$ times a factor of 0.91 . It has previously been shown that the mean specific activity of plasma water in the adult animal equals the specific activity measured at 60 min after the injection of the bolus of $\left[{ }^{3} \mathrm{H}\right]$ water times a factor of 1.09 (12). Thus, from these two observations, it could be further calculated that the mean specific activity of fetal plasma water over the 1-h experimental period equaled the specific activity of the maternal plasma water measured at 60 min times a factor of 0.99 , i.e., 1.09 times 0.91 . This factor, therefore, was used in all subsequent experiments to calculate the rates of fetal sterol synthesis.

Determination of the number of hydrogen atoms from plasma water incorporated into cholesterol. To make valid comparisons between rates of $\left[{ }^{3} \mathrm{H}\right]$ water incorporation into cholesterol in maternal and fetal tissues, it was next necessary to establish the number of protons from body water that were incorporated into sterols by the adult and fetal animals. In these studies, young virgin female rats were placed in gang cages and fed a cholesterol-free diet and given drinking water labeled with $\left[{ }^{3} \mathrm{H}\right]$ water of a known specific activity for $2 \mathrm{wk}$. They were then mated and allowed access to the same diet and drinking water for 21 more days, at which time they were killed. The specific activity of the fetal and maternal plasma water was determined and the specific activity of cholesterol isolated from the fetuses, placentas, and maternal livers was measured. It should be emphasized that in this study where there was no dietary source of cholesterol, sterol in the maternal liver and in the fetus had to be synthesized under condi-

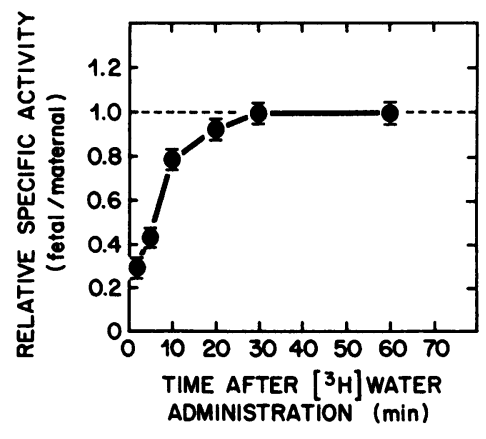

Figure 3. Plasma water relative specific activity in fetuses compared to coincident values in the respective dams. Pregnant rats in late gestation (20-22 d) were administered $100 \mathrm{mCi}$ of $\left[{ }^{3} \mathrm{H}\right]$ water intravenously as a bolus. Groups of animals were then killed at various time points over the subsequent $60 \mathrm{~min}$. Blood was taken from each dam and from her fetuses. The fetal blood was pooled in each animal. Fetal plasma had been determined to contain a higher water content $(0.96 \pm 0.02 \mathrm{ml}$ water $/ \mathrm{ml}$ plasma $)$ than maternal plasma $(0.92 \pm 0.02 \mathrm{ml}$ water $/ \mathrm{ml}$ plasma). These values were used to calculate the absolute specific activity of the plasma water, and the value found in the pooled fetal plasma was then divided by the value found in the dam. Each value represents the mean \pm 1 SEM of data obtained in three to five animals at each time point. tions where the body pools of water were labeled at a constant and known specific activity with $\left[{ }^{3} \mathrm{H}\right]$ water.

At the termination of this experiment the specific activity of water was essentially identical in the maternal plasma $(0.40 \pm 0.02 \mathrm{dpm} / \mathrm{nmol})$ and in the fetal plasma $(0.38 \pm 0.01$ $\mathrm{dpm} / \mathrm{nmol}$ ). As summarized in Table I, there were 22.0 \pm 0.4 $\mu \mathrm{g}$ atoms of $\mathrm{H}$ from water incorporated into each micromole of cholesterol in the fetus, while $\sim 19-\mu \mathrm{g}$ atoms were found in the sterols of the placenta and maternal liver. Thus, these studies demonstrated that in the fetus newly synthesized cholesterol contained $22-\mu \mathrm{g}$ atoms of $\mathrm{H}$ derived from plasma water just as has been reported for the newly synthesized sterols of the liver and other tissues of the adult rat $(14,15)$. The slightly lower value, i.e., 19- $\mu$ g atoms, found in the maternal hepatic sterols in these studies probably reflects the fact that after only 5 wk of exposure to $\left[{ }^{3} \mathrm{H}\right]$ water, there is still a small amount of unlabeled cholesterol in the peripheral tissues of the adult animal that slowly exchanges with the hepatic sterols giving an apparent incorporation rate that is slightly low. When animals are raised from weaning to adulthood on $\left[{ }^{3} \mathrm{H}\right]$ water, $22-\mu \mathrm{g}$ atoms of $\mathrm{H}$ are found in each micromole of hepatic sterols (15). Thus, this study clearly confirmed that the fetus, like the adult rat, incorporated $\sim 22-\mu \mathrm{g}$ atoms of hydrogen into each micromole of newly synthesized sterol and, therefore, it was valid to compare rates of sterol synthesis measured in vivo in the fetus and adult by comparing the nanomoles (or micromoles) of $\left[{ }^{3} \mathrm{H}\right]$ water that are incorporated into sterols under in vivo conditions.

Determination of sterol synthesis rates in vivo. Thus, experiments were next undertaken to measure absolute rates of cholesterol synthesis simultaneously in the mothers and developing fetuses. Three time points were chosen during the third trimester of the 22-d rat gestation period. This interval in the

Table I. Hydrogen Atom Incorporation into the Cholesterol Molecule*

\begin{tabular}{llcc}
\hline & \multicolumn{1}{c}{ Fetus } & Placenta & Dam (liver) \\
\hline \multirow{4}{*}{ Individual animals } & \multicolumn{3}{c}{$\mu$ g atoms of $H$ per $\mu$ mol of cholesterol } \\
& 22.8 & 20.2 & 19.3 \\
& 22.5 & & \\
& 20.7 & 18.7 & 19.1 \\
& 22.9 & & \\
& 20.6 & 18.3 & 18.6 \\
Mean & 22.6 & & \\
& $22.0 \pm 0.4$ & $19.1 \pm 0.5$ & $19.0 \pm 0.2$
\end{tabular}

* In these studies female rats were impregnated after being fed a cholesterol-free diet and allowed access to drinking water containing $\left[{ }^{3} \mathrm{H}\right]$ water at a constant specific activity for $2 \mathrm{wk} .21 \mathrm{~d}$ later fetuses, placentas, and the livers of the dams were harvested for study. Under these conditions essentially all cholesterol in the liver of the dam and in the fetus was synthesized in the presence of a pool of body water that was radiolabeled at a constant and known specific activity. Each tissue was saponified and the nonsaponifiable lipids were extracted with ether. The mass and radioactivity specifically in cholesterol was then measured after separation of the nonsaponifiable lipids using HPLC. Using the specific activity of the $\left[{ }^{3} \mathrm{H}\right]$ water in the plasma at the time the animals were killed and the specific activity of the cholesterol obtained from each tissue, it was possible to calculate the microgram atoms of hydrogen that were incorporated into each micromole of cholesterol from the pool of body water. 
pregnancy is notable for elevated maternal plasma lipids (Fig. 1) and for high rates of maternal hepatic cholesterol synthesis $(24,25)$. Furthermore, the third trimester is a period of exponential growth for the fetus (Fig. 2). In the first set of experiments, rates of total body cholesterol synthesis were measured in fetal and pregnant rats at several different days of gestation and these were compared to the rates of synthesis found in virgin female control rats. These rates of synthesis were corrected for the slight differences that existed in the content of body water in these three groups of animals, and the rates were then normalized to a standard body weight of $100 \mathrm{~g}$.

As shown in Fig. 4, total body cholesterol synthesis was relatively constant in the virgin and pregnant adult animals, although there was a slightly higher rate of sterol synthesis $(19.3 \pm 1.5 \mu \mathrm{mol} / \mathrm{h}$ per $100 \mathrm{~g}$ body $\mathrm{wt})$ in the dams at day $17 \mathrm{of}$ the pregnancy. However, at every time tested the rate of cholesterol synthesis in the fetuses was much higher than in the dams and, at $17 \mathrm{~d}$, was three times higher $(63 \pm 2.9 \mu \mathrm{mol} / \mathrm{h}$ per $100 \mathrm{~g}$ body $\mathrm{wt}$ ) than observed in the mothers. It is notable that this high rate of sterol synthesis occurred coincident with the initiation of the period of most marked fetal weight gain (Fig. 2).

The content of newly synthesized sterol $\left(\left[{ }^{3} \mathrm{H}\right] \mathrm{DPS}\right)$ in the individual tissues of the dams was next measured using a similar protocol. As summarized in Fig. 5, the content of [ $\left.{ }^{3} \mathrm{H}\right] \mathrm{DPS}$ varied markedly in the different organs of virgin rats (day 0 ). The liver contained very large amounts of newly synthesized sterol $(2,150 \pm 123 \mathrm{nmol} / \mathrm{h}$ per $\mathrm{g})$ while large tissues such as carcass contained extremely small amounts $(37 \pm 4 \mathrm{nmol} / \mathrm{h}$ per g). These contents remained relatively constant in the pregnant animals throughout gestation although, as also shown in Fig. 5, there was an apparent increase in synthesis at day 17. This was particularly true in the liver where the content of [ $\left.{ }^{3} \mathrm{H}\right] \mathrm{DPS}$ reached $3,018 \pm 254 \mathrm{nmol} / \mathrm{h}$ per $\mathrm{g}$ as compared to a value of $2,150 \pm 123 \mathrm{nmol} / \mathrm{h}$ per $\mathrm{g}$ in the virgin control animals. At this time point the content of $\left[{ }^{3} \mathrm{H}\right] \mathrm{DPS}$ in the liver equaled $71 \%$ of the total sterol newly synthesized in the pregnant animal and accounted for nearly all of the increase in total body sterol synthesis observed at the 17th day of gestation (Fig. 4). Despite these differences in synthesis rates, however, the amount of cholesterol in the liver (expressed as $\mathrm{mg} / \mathrm{g}$ wet $\mathrm{wt}$ ) remained constant throughout the pregnancy.

In the tissues associated with the fetus, there were also striking differences in the contents of newly synthesized sterol. As shown in Fig. 6, both the placenta and adjacent uterine

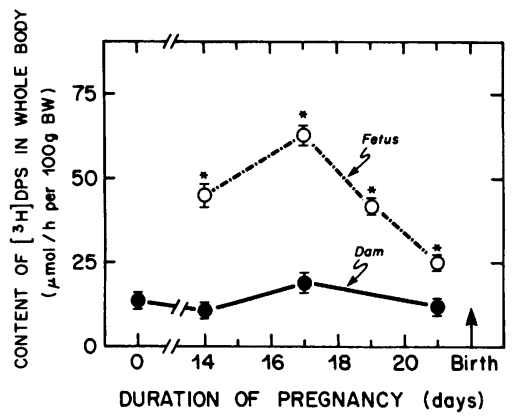

Figure 4. Content of newly synthesized sterol in the whole body of the dams and fetuses. The animals were killed $1 \mathrm{~h}$ after the intravenous administration of $\left[{ }^{3} \mathrm{H}\right]$ water and the tissues were removed, weighed and assayed for their content of $\left[{ }^{3} \mathrm{H}\right]-$ DPS. These contents in all organs were com-

bined and are expressed in this diagram as the micromoles of $\left[{ }^{3} \mathrm{H}\right]-$ water incorporated into DPS per hour per $100 \mathrm{~g}$ of body weight. The data represent mean values \pm 1 SEM for results obtained in three to five dams and in 17-35 fetuses at each time point.

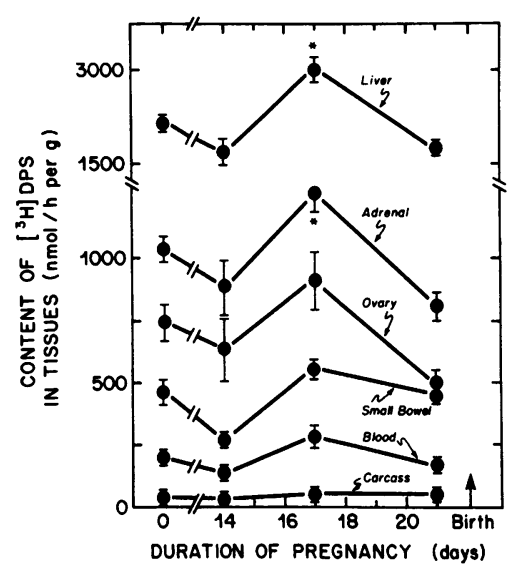

Figure 5. Content of newly synthesized sterol in several tissues of the dams at different times during the pregnancy. All animals were killed $1 \mathrm{~h}$ after the intravenous administration of $\left[{ }^{3} \mathrm{H}\right]$ water, and individual tissues were removed. These contents are expressed as the nanomoles of $\left[{ }^{3} \mathrm{H}\right]$ water incorporated into DPS per hour per gram of tissue. The data represent mean values \pm 1 SEM for three to five animals at each time point.

decidua contained little newly synthesized sterol throughout the latter part of the gestational period. In contrast, the fetal membranes had relatively high contents of the $\left[{ }^{3} \mathrm{H}\right] \mathrm{DPS}$ at days $14(824 \pm 49 \mathrm{nmol} / \mathrm{h}$ per $\mathrm{g})$ and $17(701 \pm 60 \mathrm{nmol} / \mathrm{h}$ per g) although the apparent rates of cholesterol synthesis dropped to near zero $(46 \pm 7 \mathrm{nmol} / \mathrm{h}$ per $\mathrm{g})$ just before birth. It should be noted that the peak rate of apparent cholesterol synthesis in the whole fetus was $630 \pm 29 \mathrm{nmol} / \mathrm{h}$ per $\mathrm{g}$ and this value was similar to that found in the fetal membranes at the same time in the pregnancy. In contrast, however, cholesterol synthesis in the fetus remained relatively high until birth while synthesis in the other tissues dropped to very low levels. Again, throughout gestation the amount of cholesterol in the fetus remained constant at $1.9 \pm 0.15 \mathrm{mg}$ per $\mathrm{g}$ of fetal wet wt.

Thus, these data revealed that the rate of apparent sterol synthesis in the whole fetus was severalfold higher than the rate of synthesis in the whole dam (Fig. 4) suggesting that de novo synthesis might be a major source for fetal sterol. However, when expressed per gram of tissue, it was clear that the maternal liver $(1,702$ to $3,018 \mathrm{nmol} / \mathrm{h}$ per $\mathrm{g})$ had a much higher content of $\left[{ }^{3} \mathrm{H}\right] \mathrm{DPS}$ than the fetus and fetal membranes. Furthermore, it has been well demonstrated that even during the short 60 -min period over which the synthetic rates were measured, there are significant shifts of $\left[{ }^{3} \mathrm{H}\right] \mathrm{DPS}$ from the organs

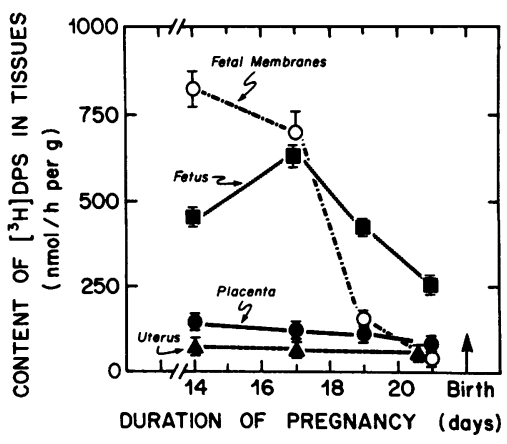
values \pm 1 SEM for results obtained in 7-27 samples taken from three to five animals at each time point. 
where synthesis takes place to other tissues (16). These observations raised the possibility that the relatively high contents of [ ${ }^{3} \mathrm{H}$ ]DPS found in the fetus might actually represent sterol that was newly synthesized in a maternal organ such as the liver and that was subsequently transferred, either by a specific lipoprotein transport system or by simple isotope exchange, across the placenta to the fetus.

Experiments to differentiate these two possibilities were next undertaken. Clearly, transfer of newly synthesized cholesterol between organs must take place through the blood. However, prior experiments have shown that during the 60 min after administration of the $\left[{ }^{3} \mathrm{H}\right]$ water essentially all newly synthesized cholesterol that appears in the blood comes from the liver $(14,16)$. When hepatic sterol synthesis is suppressed to nearly zero essentially all $\left[{ }^{3} \mathrm{H}\right] \mathrm{DPS}$ disappears from the blood. This manipulation was used to identify the source of the newly synthesized cholesterol found in the fetus. At day 13 of the gestational period a group of pregnant animals was placed on a high-cholesterol diet while a second group of animals was maintained on the normal low-cholesterol chow diet. $4 \mathrm{~d}$ later rates of cholesterol synthesis were quantitated in the various tissues of the dams and fetuses. As illustrated in Fig. 7, high contents of $\left[{ }^{3} \mathrm{H}\right] \mathrm{DPS}$ was again observed in the maternal tissues and in the fetuses of the animals fed the low-cholesterol diet. Cholesterol feeding for $4 \mathrm{~d}$ markedly suppressed hepatic cholesterol synthesis in the dams (from 3,018 \pm 254 to $181 \pm 90$ $\mathrm{nmol} / \mathrm{h}$ per $\mathrm{g}$ ) and, as anticipated, newly synthesized sterol essentially disappeared from the blood $(283 \pm 48$ to $16 \pm 4$ $\mathrm{nmol} / \mathrm{h}$ per $\mathrm{g}$ ). Since the rates of sterol synthesis in situ in the adrenal gland and ovary are known to be very low in the rat (7), this reduction in blood $\left[{ }^{3} \mathrm{H}\right]$ DPS was accompanied by a marked reduction in the content of newly synthesized sterols in these two endocrine glands, i.e., most of the newly synthesized sterol in the maternal endocrine organs came from the blood after being synthesized in the liver (7). In contrast, however, suppression of hepatic sterol synthesis in the dams had essentially no effect on the content of newly synthesized sterols in the fetuses or in the placentas and fetal membranes. Furthermore, the amount of cholesterol in the fetuses remained

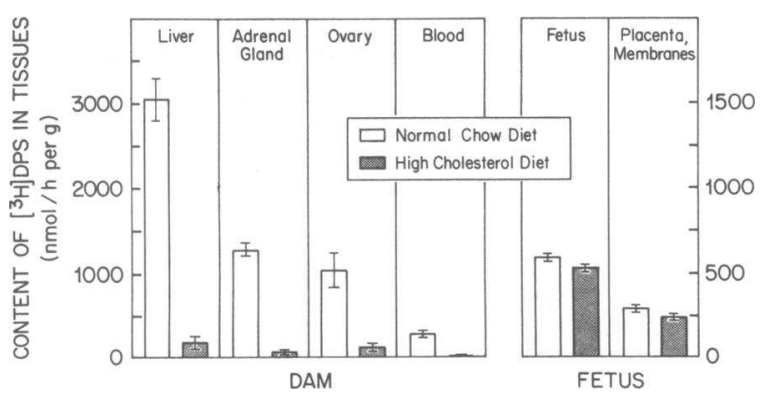

Figure 7. Relationship between the blood and tissue content of $\left[{ }^{3} \mathrm{H}\right]-$ DPS in the dam, fetus, and placenta and fetal membranes, with and without inhibition of maternal hepatic cholesterol synthesis. Rats with identical dates of impregnation were placed on either a $2 \%$ cholesterol diet for $4 \mathrm{~d}$ or on a low-cholesterol chow. All animals were then studied at a gestational age of $17 \mathrm{~d}$ when hepatic cholesterol synthesis was maximal. The content of $\left[{ }^{3} \mathrm{H}\right] \mathrm{DPS}$ was measured in maternal liver, adrenal gland, ovary and blood, and in the whole fetus and placenta plus fetal membranes in both groups. The results represent the means \pm 1 SEM of data obtained in three to five pregnant rats and 18 fetuses and combined placentas and fetal membranes. constant even though that in the maternal liver increased markedly. This finding clearly established that the high content of $\left[{ }^{3} \mathrm{H}\right] \mathrm{DPS}$ in the tissues of the fetal compartment actually represented high rates of cholesterol synthesis in situ in these tissues.

Measurement of LDL clearance by the placenta and fetus. Since placental trophoblasts are known to specifically bind LDL in vitro (11), a final set of studies was undertaken to determine if LDL was cleared from the plasma by the placenta and fetus under these same in vivo conditions. Utilizing a constant infusion technique it has been possible to quantitate the absolute rates of LDL transport into the various organs of the rat, hamster and other species and to account for whole animal LDL turnover in quantitative terms (3-5). This technique was next applied to the pregnant rat at the mid-point of the third trimester when fetal growth was maximal. As illustrated in Fig. 8, the rates of LDL clearance into the tissues of the pregnant rat showed a similar pattern to that reported in the virgin female animal (4). The highest rates of clearance, when expressed per $\mathrm{g}$ of tissue, were found in the liver and endocrine glands $(A)$. However, when these rates were multiplied by organ weights only the liver manifested a significant rate of $\mathrm{LDL}$ uptake $(C)$. The placenta did have a significant rate of LDL clearance. This rate was much lower than seen in the endocrine glands and liver when expressed per $g$ of tissue $(B)$, but was considerably higher than the two endocrine glands when expressed per whole organ $(D)$. Finally, and of greatest importance, there was no detectable uptake of the radiolabeled apolipoprotein B of LDL across the placenta into the fetus. These findings are compatible with other more indirect data $(10,11)$ suggesting that the placenta is partially dependent upon maternal cholesterol to meet its sterol needs, whereas the fetus is virtually autonomous and can synthesize all of the cholesterol that it requires.

\section{Discussion}

One of the most fundamental needs of living cells in higher animals is a continuous source of cholesterol with which to

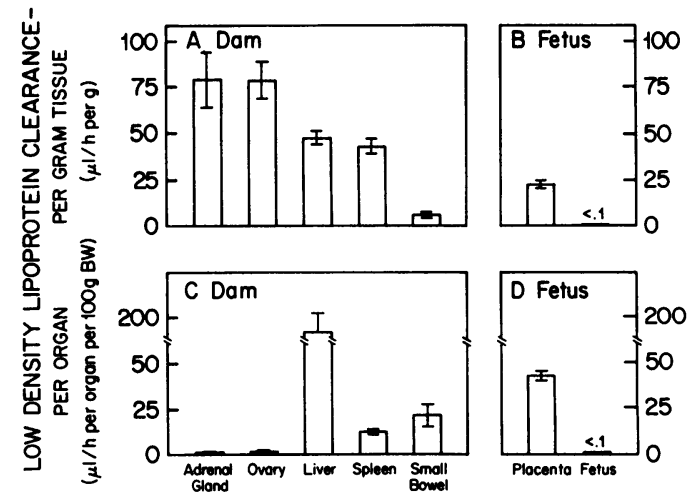

Figure 8. Total LDL clearance by various tissues of the pregnant rat and by the placenta and fetus in late gestation (gestational age of 17 d). In $A$ and $B$ clearance rates are expressed as the microliters of plasma cleared of LDL per hour per gram of maternal tissue, placenta, and fetus. In $C$ and $D$ these clearance rates are corrected to whole organ or whole fetus weights after normalization to a standard body weight of $100 \mathrm{~g}$. The data represent mean values \pm 1 SEM for determinations made in six pregnant rats. 
meet the demands for normal membrane sterol turnover and for the synthesis and differentiation of new membranous structures. It is now clear that in the immature and adult animal this need is primarily met through local cholesterol synthesis from acetyl-CoA within each organ system $(1,6)$. In general, the rates of such synthesis are highest during the phase of rapid growth in the young animal and diminish as the animal ages $(2,26)$. The developing fetus has an especially great need for new sterol since this is the period of most rapid body growth (expressed per kilogram of body weight) when 1.5-2.0 $\mathrm{mg}$ of cholesterol, on average, are required for each $1.0 \mathrm{~g}$ increase in fetal body weight. Obviously, special mechanisms must be available to supply the fetus with this large quantity of sterol if normal fetal development is to occur.

In the case of birds, on the one hand, the mother synthesizes the necessary cholesterol and deposits it in the yolk sac of the egg. This sterol is then transported to the developing embryo and used for tissue growth. There is apparently significant de novo cholesterol synthesis only in the brain of the embryo (27) so that there is little or no net increase in the total content of cholesterol in the egg over the entire period of incubation. In the chicken, for example, the newly laid egg contains 170-350 $\mathrm{mg}$ of sterol while the cholesterol present in the tissues of the newborn chick totals 169-297 mg (27). This method has obvious advantages to the bird in that "pre-synthesis" of cholesterol by the mother makes it unnecessary to provide the egg with the substrates and energy sources necessary to synthesize de novo nearly $300 \mathrm{mg}$ of sterol. The viviparous vertebrate, on the other hand, has two options available to it. The mother might synthesize the needed sterol in some organ such as the liver and then transport the cholesterol, presumably in a lipoprotein such as LDL, to the fetal compartment. Alternatively, the mother could provide a constant supply of substrates across the placenta, and these, in turn, could be used by the fetus to synthesize the needed cholesterol. Even though previous studies have demonstrated the movement of radiolabeled cholesterol from the maternal circulation to the fetus (28-31), it is still not clear whether this represents only bidirectional, monomolecular sterol exchange or does, indeed, represent net transfer of sterol to the fetal compartment.

The difficulty involved in resolving whether the fetus acquires its sterol predominantly through de novo synthesis or by uptake from the maternal circulation derives primarily from the lack of adequate methodologies for measuring rates of sterol synthesis in the fetus, in vivo. As has been reviewed in detail $(13,14)$, such rates cannot be obtained using ${ }^{14} \mathrm{C}$-labeled substrates since there are numerous unknowns in using this method including the rates of penetration of these substrates across the placenta and cells of the fetal tissues and the degree of intracellular dilution of the specific activity of the $\left[{ }^{14} \mathrm{C}\right]-$ acetyl-CoA generated from these substrates. In theory, a substrate such as $\left[{ }^{3} \mathrm{H}\right]$ water would be more useful in making such measurements since this molecule should rapidly equilibrate across the placenta and be incorporated into newly synthesized sterol within the developing fetus. However, before the absolute magnitude of synthesis can be measured with this substrate and compared with rates of synthesis obtained simultaneously in the mother, it is essential to have data on three technical aspects of this assay system. First, a detailed timecourse is required for the rate of transfer of $\left[{ }^{3} \mathrm{H}\right]$ water across the placenta from the mother; second, the number of microgram atoms of water incorporated into each molecule of fetal sterol must be known; and third, the magnitude of cholesterol transfer across the placenta must be measured.

As would be anticipated, when tested directly, there was rapid movement of $\left[{ }^{3} \mathrm{H}\right]$ water between the maternal and fetal circulations (Fig. 3) so that during the 1-h period over which rates of synthesis were measured, the mean specific activity of the water in the fetal plasma was $91 \%$ of the specific activity found in the maternal plasma. This factor could then be used to calculate the specific activity of this radiolabeled substrate in the fetus from the value measured in the maternal plasma of each animal at the end of the 1-h assay period. It was further demonstrated, under circumstances where the mothers were inseminated and the fetuses were allowed to develop in the presence of a pool of body water labeled at a constant specific activity with $\left[{ }^{3} \mathrm{H}\right]$ water, that $\sim 22-\mu \mathrm{g}$ atoms of $\mathrm{H}$ from water were incorporated into each $\mu \mathrm{mol}$ of newly synthesized sterol in the fetus (Table I). This value is essentially identical to that obtained in the adult rat in several other studies (13-15) and corresponds to a $\mathrm{H} / \mathrm{C}$ incorporation ratio of $\sim 0.61$ when expressed as the microgram atoms of $\mathrm{H}$ incorporated per micromole of acetyl-CoA entering the cholesterol biosynthetic pathway. Thus, it was possible to legitimately compare absolute rates of sterol synthesis in the mother and fetus provided, of course, that the newly synthesized cholesterol found in the fetus had not been totally acquired from the maternal circulation.

This latter point could be easily evaluated by taking advantage of the observation that over the $1-\mathrm{h}$ period that these measurements were made, essentially all $\left[{ }^{3} \mathrm{H}\right] \mathrm{DPS}$ that appeared in the plasma compartment came from the liver (14, 16). Thus, in the adult rat, and in other species, when hepatic cholesterol synthesis is suppressed, radiolabeled cholesterol in the plasma essentially disappears even though sterol synthesis in a number of other organs continues at high rates. This same effect was observed in the present studies where cholesterol feeding suppressed hepatic cholesterol synthesis by $94 \%$ and the content of $\left[{ }^{3} \mathrm{H}\right]$ cholesterol in the maternal plasma was also reduced by $94 \%$ (Fig. 7). However, despite the near absence of $\left[{ }^{3} \mathrm{H}\right]$ cholesterol in the maternal plasma, there was virtually no change in the content of newly synthesized cholesterol in the fetus. Other published data have shown this same result up to 6 $h$ after administration of the $\left[{ }^{3} \mathrm{H}\right]$ water (25). These results indicated that the $\left[{ }^{3} \mathrm{H}\right]$ cholesterol found in the fetal compartment was synthesized in that compartment. Furthermore, since both the specific activity of the $\left[{ }^{3} \mathrm{H}\right]$ water and the $\mathrm{H} / \mathrm{C}$ incorporation ratio in the fetus were known, the absolute rates of cholesterol synthesis in the fetus could be calculated and compared directly to those rates obtained simultaneously in the maternal tissues.

While these findings suggested that most, if not all, of the sterol required for fetal growth was synthesized in situ, it also was apparent in these studies that two other tissues within the fetal compartment actively incorporate $\left[{ }^{3} \mathrm{H}\right]$ water into cholesterol. These included the chorioallantoic placenta and, a lesser studied organ, the fetal membrane or parietal yolk sac. This latter tissue, elaborated from the fetal side of the chorioallantoic placenta, consists of an outer cell layer of cytotrophoblasts, a basement membrane (Reichert's membrane) and an inner cell layer of endoderm (32). This membrane encloses the cavity containing the amniotic fluid, fetus and umbilical vascular structures and is attached to the fetal side of the chorioallantoic placenta. The fetal membrane is a key extraem- 
bryonic fetal organ with an important structural function (32), and, in addition, this tissue has been shown to produce the steroid hormone, progesterone (33), and has been identified as a site for the synthesis of apolipoproteins A-I and B $(34,35)$. Despite its importance to the fetus, virtually nothing is known of its cholesterol synthetic capacity. The present study shows that early in the third trimester, during a period of rapid growth and differentiation, the rate of sterol synthesis in this membrane is nearly twice as high as in the fetus itself (Fig. 6). However, after the eighteenth day of gestation, protein synthesis in this fetal membrane ceases and cellular degeneration begins $(36,37)$. As also shown in Fig. 6 , these changes are accompanied by a dramatic decrease in the rate of sterol synthesis to about $6 \%$ of that seen on the 14th day of gestation. In contrast to the fetal membranes, sterol synthesis in the chorioallantoic placenta remained low and relatively constant throughout gestation (Fig. 6). However, while the placenta had a relatively low rate of cholesterol synthesis, it did clear LDLcholesterol from the maternal plasma (Fig. 8). This finding is consistent with other studies showing in vitro LDL binding and utilization of LDL-cholesterol for hormone synthesis by human placental trophoblasts (11).

Taken together, these studies indicate that most, if not all, of the cholesterol required for growth of the fetus and fetal membranes can be accounted for by de novo synthesis within the fetal compartment. The rates of such synthesis change dramatically to accommodate for changes in the rates of growth of these two tissues at different times during gestation (Fig. 6). There is no detectable transfer of the radiolabeled apolipoprotein B from LDL in the maternal circulation to either of these tissues (Fig. 8). Furthermore, there is virtually no exchange of radiolabeled cholesterol from the maternal circulation to the fetus or fetal membranes (Fig. 7). Such bidirectional, isotopic exchange can be demonstrated, but only after much longer periods of time (28-31). Thus, there appears to be virtually no utilization of maternal cholesterol to support either the fetus or its membranes so that the fetus is largely self-sufficient with respect to making its own sterol. In contrast, the placenta has much lower rates of sterol synthesis but clears LDL-cholesterol at a rate of nearly $25 \mu \mathrm{l} / \mathrm{h}$ per $\mathrm{g}$, and so may use both de novo synthesis and LDL-cholesterol to meet its needs for growth and hormone production.

If these results can be shown to apply to other species, as appears to be the case, then they may point up a fundamental difference in sterol metabolism between birds and viviparous animals. In the case of birds, the sterol required for construction of the embryo is presynthesized by the mother and deposited in the egg for use in membrane synthesis during the incubation period. In contrast, the fetus of viviparous animals appears to synthesize most of the sterol that it requires for growth and differentiation. Presumably, the role of the mother in this case is to make available a continuous supply of substrate across the placenta to provide both energy and acetyl-CoA units for cholesterol biosynthesis.

\section{Acknowledgments}

This work was supported by U. S. Public Health Service research grants HL-09610 and AM-19329, and by a grant from the Moss Heart Fund. Dr. Belknap was aided by grant IN-142 from the American Cancer Society and, in part, by BRSG RR-0546 awarded by the Bio- medical Research Support Grant Program, Division of Research Resources, National Institutes of Health, by grant 86G-079 of the American Heart Association, Texas Affiliate and by Basil O'Connor Starter Scholar Research Award 5-555 from the March of Dimes Birth Defects Foundation.

\section{References}

1. Spady, D. K., and J. M. Dietschy. 1983. Sterol synthesis in vivo in 18 tissues of the squirrel monkey, guinea pig, rabbit, hamster, and rat. J. Lipid Res. 24:303-315.

2. Dietschy, J. M., T. Kita, K. E. Suckling, J. L. Goldstein, and M. S. Brown. 1983. Cholesterol synthesis in vivo and in vitro in the WHHL rabbit, an animal with defective low density lipoprotein receptors. J. Lipid Res. 24:469-480.

3. Spady, D. K., D. W. Bilheimer, and J. M. Dietschy. 1983. Rates of receptor-dependent and -independent low density lipoprotein uptake in the hamster. Proc. Natl. Acad. Sci. USA. 80:3499-3503.

4. Spady, D. K., S. D. Turley, and J. M. Dietschy. 1985. Receptorindependent low density lipoprotein transport in the rat in vivo. Quantitation, characterization, and metabolic consequences. J. Clin. Invest. 76:1113-1122.

5. Spady, D. K., M. Huettinger, D. W. Bilheimer, and J. M. Dietschy. 1987. Role of receptor-independent low density lipoprotein transport in the maintenance of tissue cholesterol balance in the normal and WHHL rabbit. J. Lipid Res. 28:32-41.

6. Dietschy, J. M., D. K. Spady, and E. F. Stange. 1983. Quantitative importance of different organs for cholesterol synthesis and lowdensity-lipoprotein degradation. Biochem. Soc. Trans. 11:639-641.

7. Spady, D. K., and J. M. Dietschy. 1985. Rates of cholesterol synthesis and low-density lipoprotein uptake in the adrenal glands of the rat, hamster and rabbit in vivo. Biochim. Biophys. Acta. 836:167175.

8. Turley, S. D., and J. M. Dietschy. 1988. The metabolism and excretion of cholesterol by the liver. In The Liver: Biology and Pathobiology. 2nd Ed. I. M. Arias, W. B. Jakoby, H. Popper, D. Schachter, and D. A. Shafritz, editors. Raven Press, Ltd., New York. 617-641.

9. Carr, B. R., and E. R. Simpson. 1982. Cholesterol synthesis in human fetal tissues. J. Clin. Endocrinol. Metab. 55:447-452.

10. Carr, B. R., W. E. Rainey, and J. I. Mason. 1985. 3-hydroxy-3methylglutaryl coenzyme A reductase in anencephalic and normal human fetal liver. J. Clin. Invest. 76:1946-1949.

11. Winkel, C. A., P. C. MacDonald, P. G. Hemsell, and E. R. Simpson. 1981. Regulation of cholesterol metabolism by human trophoblastic cells in primary culture. Endocrinology. 109:1084-1090.

12. Jeske, D. J., and J. M. Dietschy. 1980. Regulation of rates of cholesterol synthesis in vivo in the liver and carcass of the rat measured using $\left[{ }^{3} \mathrm{H}\right]$ water. J. Lipid Res. 21:364-376.

13. Andersen, J. M., and J. M. Dietschy. 1979. Absolute rates of cholesterol synthesis in extrahepatic tissues measured with ${ }^{3} \mathrm{H}$-labeled water and ${ }^{14} \mathrm{C}$-labeled substrates. J. Lipid Res. 20:740-752.

14. Dietschy, J. M., and D. K. Spady. 1984. Measurement of rates of cholesterol synthesis using tritiated water. J. Lipid Res. 25:14691476.

15. Spady, D. K, and J. M. Dietschy. 1987. Hepatic bile acid synthesis: studies on regulation utilizing rats whose total body pool of cholesterol is uniformly labelled with ${ }^{3} \mathrm{H}$. In Bile Acids and The Liver. G. Paumgartner, A. Stiehl, and W. Gerok, editors. MTP Press Limited, Lancaster, England. 15-24.

16. Turley, S. D., J. M. Andersen, and J. M. Dietschy. 1981. Rates of sterol synthesis and uptake in the major organs of the rat in vivo. $J$. Lipid Res. 22:551-569.

17. Pittman, R. C., A. D. Attie, T. E. Carew, and D. Steinberg. 1979. Tissue sites of degradation of low density lipoprotein: Application of a method of determining the fate of plasma proteins. Proc. Natl. Acad. Sci. USA. 76:5345-5349. 
18. Pittman, R. C., and C. A. Taylor, Jr. 1986. Methods for assessment of tissue sites of lipoprotein degradation. Methods Enzymol. 129:612-628.

19. Koelz, H. R., B. C. Sherrill, S. D. Turley, and J. M. Dietschy. 1982. Correlation of low and high density lipoprotein binding in vivo with rates of lipoprotein degradation in the rat. A comparison of lipoproteins of rat and human origin. J. Biol. Chem. 257:8061-8072.

20. Spady, D. K., and J. M. Dietschy. 1985. Dietary saturated triacylglycerols suppress hepatic low density lipoprotein receptor activity in the hamster. Proc. Natl. Acad. Sci. USA. 82:4526-4530.

21. Beaudoin, A. R. 1980. Embryology and teratology. In The Laboratory Rat. H. J. Baker and J. R. Lindsey, editors. Vol. II. Academic Press, Inc., New York. 75-101.

22. Baker, D. E. J. 1979. Reproduction and Breeding. In The Laboratory Rat. H. J. Baker and J. R. Lindsey, editors. Vol. I. Academic Press, Inc., New York. 153-168.

23. Argiles, J., and E. Herrera. 1981. Lipids and Lipoproteins in maternal and fetus plasma in the rat. Biol. Neonate. 39:37-44.

24. Feingold, K. R., M. H. Wiley, G. MacRae, and M. D. Siperstein. 1980. Mevalonate metabolism in pregnant rats. Metab. Clin. Exp. 29:885-891.

25. Feingold, K. R., T. Wiley, A. H. Moser, S. R. Lear, and M. H. Wiley. 1983. De novo cholesterogenesis in pregnancy. J. Lab. Clin. Med. 101:256-263.

26. Stange, E. F., and J. M. Dietschy. 1984. Age-related decreases in tissue sterol acquisition are mediated by changes in cholesterol synthesis and not low density lipoprotein uptake in the rat. J. Lipid Res. 25:703-713.

27. Connor, W. E., R. Johnston, and D. S. Lin. 1969. Metabolism of cholesterol in the tissues and blood of the chick embryo. J. Lipid Res. 10:388-394.

28. Kayden, H. J., J. Dancis, and W. L. Money. 1969. Transfer of lipids across the guinea pig placenta. Am. J. Obstet. Gynecol. 104:564572.
29. Connor, W. E., and D. S. Lin. 1967. Placental transfer of cholesterol-4- ${ }^{14} \mathrm{C}$ into rabbit and guinea pig fetus. J. Lipid Res. 8:558564.

30. Lin, D. S., R. M. Pitkin, and W. E. Connor. 1977. Placental transfer of cholesterol into the human fetus. Am. J. Obstet. Gynecol. 128:735-739.

31. Pitkin, R. M., W. E. Connor, and D. S. Lin. 1972. Cholesterol metabolism and placental transfer in the pregnant Rhesus monkey. $J$. Clin. Invest. 51:2584-2592.

32. Clark, C. C., E. A. Tomichek, T. R. Koszalka, R. R. Minor, and N. A. Kefalides. 1975. The embryonic rat parietal yolk sac. The role of the parietal endoderm in the biosynthesis of basement membrane collagen and glycoprotein in vitro. J. Biol. Chem. 250:5259-5267.

33. Botte, V., G. Materazzi, and G. Chieffi. 1966. Histochemical distribution of $3 \beta$-hydroxy-steroid dehydrogenase and $17 \alpha$-and $17 \beta$ hydroxysteroid dehydrogenases in the placenta and foetal membranes of the rat. J. Endocrinol. 34:179-183.

34. Demmer, L. A., M. S. Levin, J. Elovson, M. A. Reuben, A. J. Lusis, and J. I. Gordon. 1986. Tissue-specific expression and developmental regulation of the rat apolipoprotein B gene. Proc. Natl. Acad. Sci. USA. 83:8102-8106.

35. Elshourbagy, N. A., M. S. Boguski, W. S. L. Liao, L. S. Jefferson, J. I. Gordon, and J. M. Taylor. 1985. Expression of rat apolipoprotein A-IV and A-I genes: mRNA induction during development and in response to glucocorticoids and insulin. Proc. Natl. Acad. Sci. USA. 82:8242-8246.

36. Clark, C. C., R. R. Minor, T. R. Koszalka, R. L. Brent, and N. A. Kefalides. 1975. The embryonic rat parietal yolk sac. Changes in the morphology and composition of its basement membrane during development. Dev. Biol. 46:243-261.

37. Jensh, R. P., T: R. Koszalka, M. Jensen, L. Biddle, and R. L. Brent. 1977. Morphologic alterations in the parietal yolk-sac of the rat from the 12th to the 19th day of gestation. J. Embryol. Exp. Morphol. 39:9-21. 